\title{
PERANCANGAN IDENTITAS DAN PROFIL PERUSAHAAN KAFE KONTAINER VESSELS
}

\author{
Dessyca Elizabeth
}

\begin{abstract}
Abstrak: Vessels merupakan jasa modifikasi dalam pembuatan kafe kontainer serta dapat menyediakan training terhadap sumber daya manusia. Perusahaan Vessels masih tergolong perusahaan baru yang berdiri sejak 2018, dikarenakan perusahaan Vessels masih tergolong baru, maka Vessels belum memiliki identitas perusahaan seperti logo. Perancangan identitas perusahaan juga meliputi dalam pengaplikasian logo terhadap media visual yang dibutuhkan seperti stationary set, business documents, uniform, vehicle dan company profile. Perancangan identitas perusahaan dibuat melalui langkah-langkah dari Alina Wheeler.
\end{abstract}

Kata kunci: identitas perusahaan, identitas visual, logo, profil perusahaan, perancangan

\section{Pendahuluan}

Seperti yang kita ketahui, semua yang dapat dibangun dan menjadi kuat itu berasal dari adanya identitas seperti diri sendiri maupun organisasi, khususnya perusahaan. Perusahaan yang mempunyai identitas dapat merepresentasikan image atau citra diri dari perusahaan tersebut. Menurut hasil penelitian dari Nielsen menyatakan bahwa " $66 \%$ of global consumers with Internet access prefer to buy new products from a familiar brand rather than switch to a new brand, according to a new study from Nielsen" (Nielsen.com, 2013). Terjemahan: "66\% dari konsumer global yang memiliki akses internet lebih memilih untuk membeli produk baru dari brand yang telah familiar dikenal lebih dulu, dibandingkan beralih kepada brand baru" (Nielsen.com, 2013).

Identitasmerupakanjatidiriyang akan

Dessyca Elizabeth adalah mahasiswi pada Program Studi Ilmu Komunikasi, Digital Media Communication and Advertising, STIKOM The London School of Public Relations, Jakarta. membentuk diferensiasi atau memiliki ciri khas. Identitas berfungsi sebagai pembeda (Kotler \& Pfoertsch, 2008). Akan hal ini, identitas adalah dasar atau inti dari terciptanya perusahaan tersebut. Perusahaan yang tidak memilki identitas akan sulit untuk bersaing.

Salah satu usaha yang banyak digemari masyarakat adalah bisnis kafe. Terbukti dari perkembangan berbagai industri bisnis, sektor food and beverages (makanan dan minuman) secara khusus menjadi salah satu yang paling pesat pertumbuhannya -yang banyak mencatat kisah kesuksesan dengan angka keuntungan yang signifikan (Idris, 2017).

Bisnis kafe yang semakin kompetitif di era digital ini juga memacu kreatifitas yang terus bermunculan -dengan konsep yang menarik, nyaman, serta branding yang kuat. Dari segala macam

e-mail : dessycaelizabeth@gmail.com 
jenis kafe, ada salah satu cara untuk membuat kafe tersebut menjadi besar secara cepat dan efektif yaitu dengan franchise. Di Indonesia, aktivitas franchise saat ini banyak dilakukan dikarenakan hal ini merupakan suatu fenomena bisnis yang baru (Solopos, 2016). Hal ini mulai banyak diminati karena kemudahan dalam persyaratan dan kategori usaha yang mudah diterima oleh masyarakat sehingga cukup pesat.

Untuk menentukan sebuah corporate identity yang tepat termasuk salah satu bentuk permasalahan yang tidak terstruktur karena banyak kriteria-kriteria yang bersifat personal dari perusahaan tersebut sehinggga tidak bisa didapatkan sebuah keputusan dengan segera. Sebagai suatu ekspresi visual, identitas perusahaan dapat diciptakan dan dijadikan tolak ukur terhadap nasib perusahaan tersebut. Perusahaan kecil, menengah hingga besar memerlukan sebuah perancangan logo dan corporate identity dimana simbol/logo merupakan aspek komunikasi antar perusahaan dan masyarakat (Setyoning, 2016, para.1). Simbol dalam berkomunikasi bukan hanya sekarang muncul, tetapi sudah pada zaman awal peradaban manusia, banyak di gunakan simbol dalam penulisan dan bertujuan untuk berkomunikasi, berperang dan menandai lokasi. Dalam buku Designing Brand Identity mengatakan bahwa "Symbols are vessels for meaning” (Wheeler, 2009, hlm.34).

Hal itu bermaksud bahwa simbol merupakan wadah perusahaan itu sendiri yang berisikan makna yang ingin disampaikan pada sasarannya. Simbol juga melibatkan kecerdasan, imajinasi, emosi, dengan cara yang tidak dilakukan pembelajaran lain (Wheeler, 2009, hlm.34). Maka dari itu, corporate identity harus mempunyai visi yang sama dengan rencana perusahaan dikarenakan hal ini menentukan penilaian pikiran dan emosi dari apa yang dili- hat oleh masyarakat akan perusahaan

Dalam lima tahun belakangan ini, harga properti, baik bangunan maupun lahan sangat meningkat pesat bahkan hampir tidak terjangkau harganya secara khususnya di kota megapolitan seperti Jakarta. Oleh karena itu, para calon wirausaha muda dan perintis bisnis yang baru cenderung memilih alternatif yang lebih murah untuk memulai bisnisnya. Para startup bisnis atau pebisnis baru melihat medium kontainer ini dapat dijadikan sebuah peluang bisnis yang sangat beragam, dan salah satunya adalah dalam bentuk kafe kontainer.

Salah satu penyedia jasa yang menyediakan kafe kontainer adalah Vessels. Vessels merupakan perusahaan yang bergerak dalam penyedia kafe kontainer yang akan didistribusikan kepada pembisnis baru atau kebutuhan tertentu. Baru tahun 2017, Vessels ini meluncurkan sebuah ide untuk menjadi penyedia jasa kontainer kafe dan saat ini sudah ada yang menggunakan jasanya yaitu Kafe 'Beyond Ropangnoodle' yang berada di daerah Bekasi. Pemilik dari Vessels ini melihat bahwa tren dari di luar negeri dengan menggunakan kafe kontainer sudah layak untuk masuk ke Indonesia karena melihat bahwa banyak pembisnis baru khususnya anak muda mempunyai keinginan tinggi untuk membuka bisnis yang unik namun bermodal rendah. Sasaran dari bisnis Vessels adalah pebisnis baru dan franchisee. Untuk memperkenalkan usaha ini kepada masyarakat, Vessels membutuhkan sebuah corporate identity yang merepresentasikan dari ciri khas dari perusahaan tersebut.

\section{Metode Penelitian}

\section{Corporate Identity}

Bernstein menyatakan bahwa "the companies should be concerned about 
their image, because they need to distinguish how they are being received and how these perceptions equate with their self-image (Jabbar, 2014, hlm. 10)." Terjemahan: "Perusahaan harus memperhatikan citra perusahaan tersebut, karena perusahaan membutuhkan perbedaan bagiamana perusahaan dapat diterima dan bagaimana persepsi selaras dengan citra diri perusahaan tersebut (Jabbar, 2014, hlm.10)." Dalam hal membangun citra diri, visual atau grafis yang nyata sangat dibutuhkan untuk memperkenalkan kepada masyarakat. Dalam jurnal yang disebarkan oleh Zeenat Jabbar menyatakan identitas visual pada sebuah perusahaan adalah wujud dasar dari sebuah komitmen perusahaan yang membentuk produk, lingkungan dan komunikasi. Ada lima komponen dasar dari sistem identitas visual perusahaan (Jabbar, 2014, hlm.11):

\section{Nama}

Penamaan pada suatu brand dapat dinilai dari pemaknaan nama tersebut dan positioning goals dari suatu perusahaan. Kecintaan terhadap nama dapat didasarkan dari makna dan asosiasi yang dibangun seiring berjalannya waktu (Wheeler, 2009, hlm. 122).

\section{Logotype}

Logotype yang baik merupakan logo yang tidak hanya mempunyai ciri khas, namun bersifat tahan lama dan berkelanjutan. Bentuk dari logo yang baik dapat dimanipulasi untuk merepresentasikan kepribadian dari suatu perusahaan (Wheeler, 2009, hlm. 126).

\section{Tipografi}

Tipografi merupakan salah satu elemen yang dapat mempertahankan identitas yang efektif. Tipografi juga dapat mendukung strategi dari positioning perusahaan dan bersifat berke- lanjutan (Wheeler, 2009, p. 132).

\section{Warna}

Warna merupakan hal yang sudah terbukti dapat mempengaruhi psikologi manusia. Warna dalam pembentukan visual identity digunakan untuk membangkitkan emosi dan mengekspresikan karakter dari perusahaan. Hal ini dapat menjadi roda percepatan terhadap diferensiasi merek (Wheeler, 2009, p. 128).

\section{Tagline}

Tagline tumbuh dari proses strategi dan kekreatifitas akan pembentukkan identitas perusahaan. Tagline adalah mantra atau kalimat perusahaan secara singkat yang dapat membantu menciptakan minat (Wheeler, 2009, p. 24).

\section{Corporate Identity Mix}

Perusahaan yang membutuhkan identitas, berarti bisa dikatakan bahwa sebenarnya perusahaan tersebut krisis akan identitas. Albert percaya dan berargumen bahwa salah satu fitur yang menentukan dari konsep identitas adalah menghindari upaya pengukuran apapun. Meski konsepnya sulit diukur, namun konsepnya masih ada sebagai fenomena dengan caranya sendiri dan identitas adalah salah satu konsep yang hanya memiliki definisi kerja, yang berfungsi untuk mengarahkan dan memberikan arahan penyelidikan (Bloch, 2013, hlm. 107).

Tidak hanya sekedar corporate identity, tetapi John Balmer mengatakan di jurnal yang berjudul Corporate identity: the concept, its measurement and management bahwa ada corporate identity mix yang diperkuat dari pernyataan,

"Starting with Olins (1978) and followed by Birkight and Stadler (1980) the 
understanding of corporate identity has gradually broadened and is now taken to indicate the way in which an organization's identity is revealed through behaviour, communications, as well as through symbolism to internal and external audiences" (Balmer, 1997, p.2).

Terjemahan: "Dimulai dengan Olins (1978) dan diikuti oleh Birkight dan Stadler (1980) pemahaman identitas perusahaan telah berangsur-angsur diperluas dan sekarang diambil untuk menunjukkan cara di mana identitas organisasi dan penonton luar." (Balmer, 1997, hlm. 2).

Pernyataan ini yang menjelaskan bahwa Identitas perusahaan terbentuk karena 3 hal yaitu perilaku, komunikasi dan simbol yang dinamai dengan Corporate Identity Mix.

\section{- Pola Perilaku / Behaviour}

Karan Rostami mengatakan "The behaviorist learning orientation is particularly useful for the development of competencies and for demonstrating technical or psychomotor skills." Terjemahan: Orientasi pada pembelajaran perilaku berguna untuk pengembangan kompetensi dan untuk menunjukkan kemampuan teknis atau psikomotorik (Rostami, 2010, hlm. 1).

\section{- Simbol}

Menurut Birkigt dan Stadler, "simbol mengacu kepada seperangkat identitas visual yang diterapkan oleh organisasi bisnis baik di tingkat perusahaan maupun produk untuk menunjukkan kepemilikan dan mencapai diferensiasi" (Otubanjo, 2013, hlm. 60).

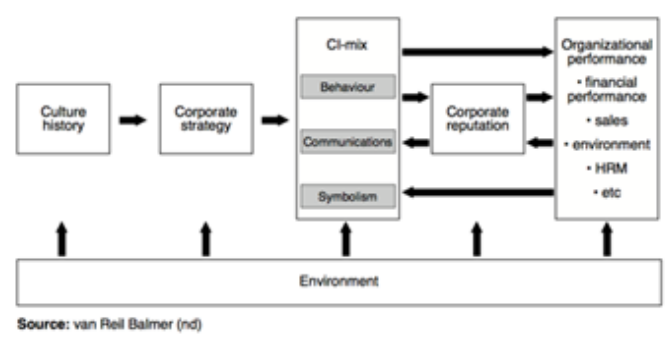

Gambar 1. Bagan Pembentukan Corporate Identity Mix (Balmer, 1997, hlm. 342)

\section{Business to Business (B2B)}

Business to business adalah model business yang berfokus pada penjualan produk dan layanan antar perusahaan. Berbeda dengan model business to consumer (B2C) yang berhubungan dengan pelanggan langsung, namun B2B berhubungan langsung dengan antar perusahaan yang menawarkan bahan baku atau layanan yang dibutuhkan perusahaan untuk meningkatkan keuntungan, dari industri manufaktur hingga ritel. Business to business bergantung pada fungsi penjualan dan tim manajemen accounting untuk membangun dan memperkuat hubungan pelanggan/ klien (Uzialko, 2017).

\section{Hasil dan Pembahasan}

\section{Langkah-langkah Perancangan Identitas Perusahaan}

Data yang diperoleh didapatkan dari hasil wawancara bersama pemilik perusahaan Vessels dan ditambahkan dengan data sekunder yang berupa internet dan buku. Tahapan perancangan menggunakan metode dari Wheeler yang berjudul Designing Brand Identity. Tahapan Pembuatan Identitas Perusahaan menurut Wheeler adalah 


\section{Conducting Research}

Riset yang cerdas dapat membentuk suatu keputusan yang baik bagi perusahaan. Tetapi, riset yang salah arah dapat menghalangi inovasi dalam perusahaan. Riset pasar adalah pengumpulan, evaluasi, dan interpretasi data yang mempengaruhi keputusan pelanggan terhadap produk, layanan, dan merek.

\section{Clarifying Strategy}

Tahap ini adanya melakukan strategi untuk keberhasilan dalam perancangan identitas perusahaan seperti menentukan fokus, penamaan sebuah brand dan juga menentukan arah kemana brand tersebut berjalan.

\section{Designing Identity}

Logo, warna, typography dan pengaplikasian design pada brand akan diuji coba dan dinilai berdasarkan estetika dan tujuan perusahaan.

\section{Creating Touchpoints}

Pengaplikasian design tersebut juga berlaku dalam pengaplikasian pada sebuah atribut brand dan ditentukan atribut yang tepat untuk brand tersebut agar perusahaan dapat berjalan dengan professional dan efesien. Atribut yang sudah ditentukan untuk brand Vessels seperti kop surat, kartu nama, seragam karyawan, balpoin, usb, surat jalan, invoice, dan amplop.

\section{Managing Assets}

Tahap ini melakukan adanya peluncuran brand terhadap targetnya. Peluncuran brand merupakan peluang yang sangat baik untuk pemasaran. Organisasi harus cerdas dalam kesempatan ini untuk membangun kesadaran merek. Organisasi yang masih kecil mungkin belum mempunyai banyak anggaran untuk menga- dakan pengumuman dengan kampanye besar-besaran, namun bisa melalui brosur atau media online yang akan dikirimkan ke pelanggan, karyawan dan investor. Launching Brand Identity sangat dibutuhkan oleh Perusahaan Vessels yang akan dirancang oleh tim pemasaran (marketing) ataupun komunikasi yang sudah ditentukan.

\section{Produksi}

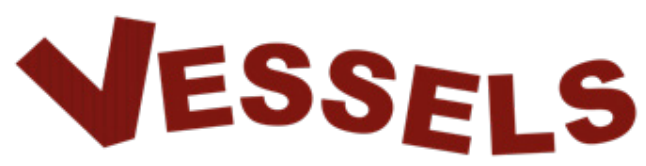

Gambar 2. Desain Logo Perusahaan Vessels (Elizabeth, 2018)

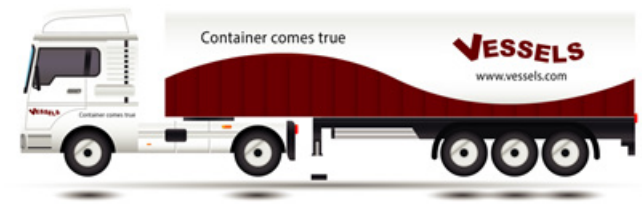

Gambar 3. Desain Kendaraan Perusahaan Vessels (Elizabeth, 2018)

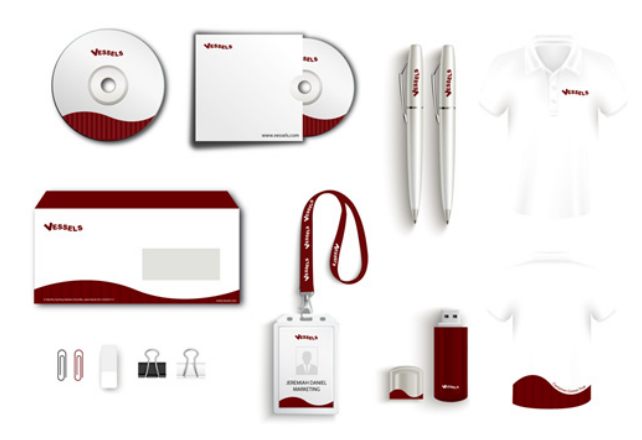

Gambar 4. Desain Stationary Kit Perusahaan Vessels (Elizabeth, 2018) 


\section{Kesimpulan}

Setelah pembuatan identitas perusahaan Vessels dalam hasil karya tersebut, pemilik Vessels merasa puas akan hasil karya ini. Hasil karya ini akan segera dipakai secara nyata untuk bisnis yang akan dibangun yaitu perusahaan Vessels. Pemilik Vessels sudah merasa nyaman dan percaya diri dengan adanya visualisasi akan identitas dari perusahaan Vessels ini. Mengenai logo juga pemilik Vessels yang memilih dari ketiga sketsa yang dibuat oleh perancang karya. Logo yang dipilih pemilik Vessels merupakan logo yang merepresentasikan dirinya dan pastinya perusahaan Vessels. Hal ini merupakan salah satu bentuk dengan adanya kepemilikan seseorang pada suatu brand (Pemilik Vessels, wawancara data primer, Juli, 10/07/2018).

\section{Rekomendasi}

Perancangan identitas dan profil perusahaan Vessels dibuat agar perusahaan Vessels mempunyai identitas yang kuat dan dapat memperlihatkan karakter dari perusahaan. Selain itu dengan adanya identitas, Vessels dapat mengidentifikasi segmentasi, melakukan pemasaran dan menjalankan bisnisnya secara mudah, tepat dan benar. Ada beberapa hal yang dapat menjadi masukan bagi perusahaan Vessels yaitu:

1. Perusahaan Vessels dapat menggunakan stationary baru untuk media promosi diluar dari stationary yang sudah dijalankan saat ini. Di luar dari stationary, Vessels dapat menggunakan media promosi yang lain seperti word of mouth atau event.

2. Perusahaan Vessels juga dapat lebih aktif di bagian promosi dalam sosial media seperti Instagram atau Facebook. Disarankan perusa- haan Vessels harus memiliki fitur chat yang mudah diakses oleh masyarakat seperti Whatsapp atau Line @. Selain fitur chat atau fitur teks, Vessels disarankan untuk membuat konten video di youtube yang menampilkan identitas Vessels dan memberi informasi akan profil perusahaan serta portofolio pada perusahaan Vessels.

\section{Referensi}

Balmer, J. M. (1997). European Journal of Marketing. Corporate Identity: The Concept, Its Measurement and Management, 31, 342. Diperoleh dari E-journal: http://www.emeraldinsight.com/doi/abs/10.1108/ ebo60635

Bloch, O. (2013). Corporate Identity and Crisis Response Strategies . Frankfurt, Germany: Springer VS.

Hadi, A. (2018). 8 Unsur Seni Rupa. Diperoleh dari website: http:// www.softilmu.com/2015/11/8-macam-unsur-unsur-seni-rupa-adalah. html

Idris, M. (2017, March 20). Modal Rp 1,3 Juta, Pemuda Ini Bisnis Kafe Susu Beromzet Ratusan Juta. Diperoleh dari website: https://finance.detik. com/solusiukm/3451051/modal-rp13-juta-pemuda-ini-bisnis-kafe-susu-beromzet-ratusan-juta

Jabbar, Z. (2014). The Impact of Corporate Visual Identity on Brand Personality. Brunel Business School, 10. Diperoleh dari E-journal: http://bura.brunel.ac.uk/bitstream/2438/8734/1/FulltextThesis.pdf

Nielsen.com. (2013, 01 22). Global Consumers More Likely to Buy New Products From Familiar Brands. 
Diperoleh dari website: http:// www.nielsen.com/us/en/pressroom/2013/global-consumers-morelikely-to-buy-new-products-from-familiar-bo.html

Otubanjo, O. (2013). The Extended Corporate Identity Mix. International Journal of Marketing Studies, 60. Diperoleh dari E-journal: www.ccsenet. org/journal/index.php/ijms/article/ viewFile/23932/15169

Psychology, C. (2018). Maroon Color. Diperoleh dari website: The Psychology of Colors and the meanings: https:// www.colorpsychology.org/maroon/

Rostami, K. (2010). The Implications of Behaviorism and Humanism theories in medical education. Research Institute for Gastroenterology and Liver Diseases, 1. Birmingham: University of Birmingham

Solopos, A. (2016, Mei 17). Bisnis Waralaba Tumbuh Pesat di Indonesia. Diperoleh dari website: https://economy.okezone.com/ $\mathrm{read} / 2016 / 05 / 17 / 320 / 1390833 /$ bisnis-waralaba-tumbuh-pesat-di-indonesia

Wheeler, A. (2009). Designing Brand Identity. New Jersey: John Wiley \& Sons, Inc. 